\title{
Electrocardiographic changes produced by interventricular septal rupture
}

\author{
F. Kerr ${ }^{1}$ and L. J. Haywood \\ From Los Angeles County-University of Southern California Medical Center, Los Angeles, California, \\ U.S.A.
}

The electrocardiogram was recorded during spontaneous rupture of the interventricular septum in a patient after myocardial infarction. The electrocardiographic abnormalities included an increase in the sinus rate, elevation of the ST segment, decrease in $Q$ wave size, and increase in the height and width of the $P$ wave.

Significant areas of necrosis are found in the interventricular septum of 60 per cent of patients dying from acute myocardial infarction (Osher and Wolff 1952). However, rupture of the septum occurs in only 1 per cent of infarct deaths (Griffith, Hegde, and Oblath, 1961). Though the electrocardiographic features of septal infarction are well recognized (Osher and Wolff, 1952), we have found only one report of electrocardiographic changes recorded at the time of septal rupture (Normand et al., 1965). We, therefore, report details of another patient in whom the electrocardiogram was recorded at the time of septal rupture.

\section{Case report}

The patient, a 69-year-old woman, was admitted to the coronary care unit with a 2-hour history of tight anterior chest pain. Though she was receiving treatment for mild hypertension with a thiazide diuretic, there was no previous history of ischaemic heart disease. At the time of admission her heart rate was $80 / \mathrm{min}$ and regular with a blood pressure of $160 / 100 \mathrm{mmHg}(21.3 / 13.3 \mathrm{kPa})$. Basal lung crepitations and a fourth heart sound were heard, but there was no radiographic evidence of pulmonary oedema. The admission electrocardiogram showed changes in keeping with an acute posteroinferior myocardial infarction (Fig. 1).

Throughout her stay in the unit the patient was confined to bed except for use of a bedside commode. Recordings of heart rate and blood pressure

1Present address: Raigmore Hospital, Inverness. were made every 4 hours. After the admission recording, the blood pressure settled within the normal range, and the clinical state remained stable, with no rhythm disturbance or advancement of cardiac failure. Thirty-eight hours after the estimated time of onset of the myocardial infarction the patient complained of sudden return of anterior chest pain. This was accompanied by the development of hypotension (systolic pressure $<100$ $\mathrm{mmHg}(13.3 \mathrm{kPa})$ and florid signs of cardiac failure. Auscultation of the praecordium shortly after the onset of chest pain revealed a parasternal pansystolic murmur and thrill which had not previously been present. Despite intensive supportive medical measures, the patient's condition continued to deteriorate and she died $2 \frac{1}{2}$ hours after the return of chest pain.

\section{Electrocardiogram}

The patient's electrocardiogram was monitored by means of a bipolar chest lead system producing a lead II configuration and observed continuously by specially trained nursing staff on a central oscilloscope. The skin electrodes were maintained in a constant position throughout the period of monitoring. A paper strip recording of the electrocardiogram could be obtained as required.

A rhythm strip obtained 6 hours before rupture (Fig. 2A), apart from atrial ectopics, showed no change from lead II of the admission electrocardiogram (Fig. 1). A record of the electrocardiogram was obtained from the moment of recurrence of chest pain and showed an immediate $3 \mathrm{~mm}$ rise in the ST segment in association with a decrease in $Q$ wave size (Fig. 2B). This was followed by a pro- 

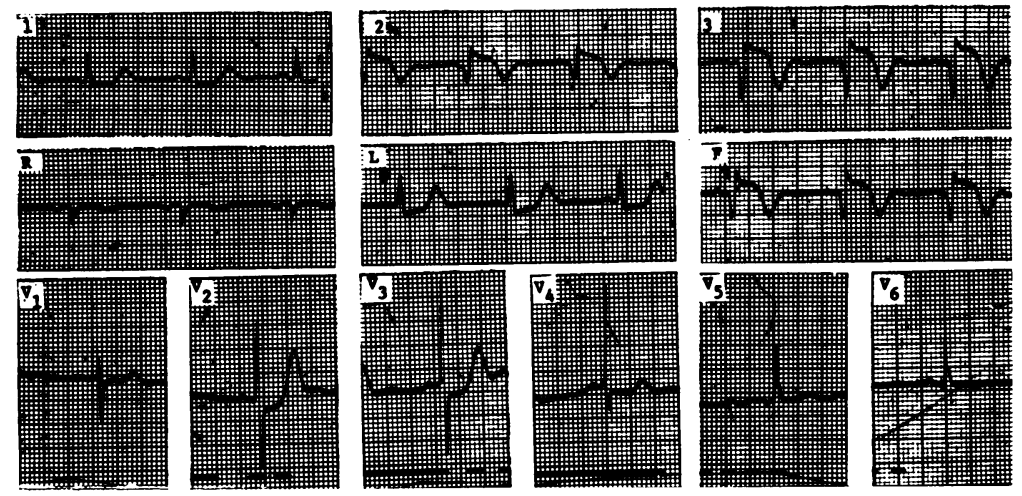

FIG. 1 Admission electrocardiogram.

gressive increase in the sinus rate, increase in $P$ wave size (Fig. 2C), and runs of supraventricular tachycardia, with further elevation of the ST segment (Fig. 2D). Death occurred after the development of advanced atrioventricular block and a terminal slow idioventricular rhythm (Fig. 2E, F).

\section{Necropsy}

Necropsy revealed a tear $(5 \mathrm{~cm} \times 3 \mathrm{~cm})$ in the centre of a large fresh septal infarct. The right main coronary artery was totally occluded close to its origin, and though the other vessels remained patent they were heavily involved by atheromatous deposits. The pericardial sac contained a very small quantity of serosanguinous fluid.

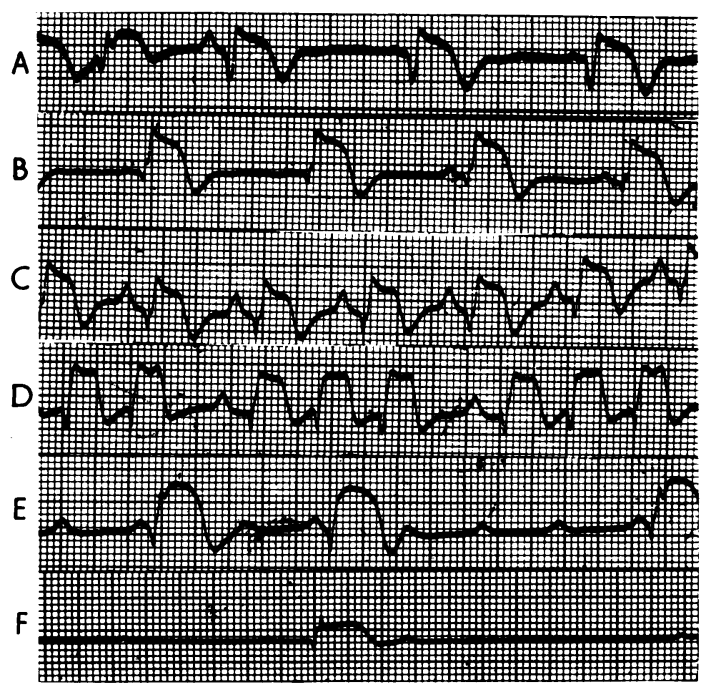

FIG. 2 Serial monitor lead recordings.

\section{Discussion}

It is probable that the moment of septal rupture was heralded by the recurrence of chest pain, since it was at this point that abrupt deterioration of the haemodynamic state occurred and the parasternal murmur was first heard. Therefore, it is reasonable to suggest that the electrocardiogram, recorded during this period, relates to the rupture event.

The recurrence of chest pain was accompanied by a further rise in the ST segment, a change usually attributed to further ischaemic injury to the myocardium. A rise in the ST segment has been described in relation to rupture of the free left ventricular wall (Friedman, Kuhn, and Katz, 1971), and indeed Mir (1972) has suggested it is an indicator of impending rupture. The sudden increase in $P$ wave size could result from right atrial strain. The appearance of such a large septal defect would produce a sizeable left-to-right interventricular shunt, with a subsequent rise in right ventricular filling pressure and a haemodynamic setting capable of producing acute right atrial strain. A similar increase in $P$ wave size has been described by Normand et al. (1965) who reported two patients with interventricular septal rupture after myocardial infarction.

Although these electrocardiographic changes do seem to have occurred as a result of septal rupture, they can hardly be termed specific. We know that other complications of myocardial infarction can produce the same changes. A rise in ST segment may simply indicate the occurrence of further myocardial injury or infarction, and an increase in $P$ wave height may result from pulmonary embolus (Wood, 1948). Likewise, rhythm disturbances and atrioventricular block are well-recognized complications in patients with myocardial infarction and and could not be attributed to septal rupture alone. Nevertheless, the changes we report, particularly 
ST segment elevation followed by increase in $P$ wave height, may add supportive evidence to a diagnosis of septal rupture occurring in the context of acute myocardial infarction.

\section{References}

Friedman, H. S., Kuhn, L. A., and Katz, A. M. (1971). Clinical and electrocardiographic features of cardiac rupture following acute myocardial infarction. American fournal of Medicine, 50, 709.

Griffith, G. C., Hegde, B., and Oblath, R. W. (1961). Factors in myocardial rupture. An analysis of two hundred and four cases at Los Angeles County Hospital between 1924 and 1959. American fournal of Cardiology, 8, 792.
Mir, M. A. (1972). M-Complex: the electrocardiographic sign of impending cardiac rupture following myocardial infarction. Scottish Medical fournal, 17, 319.

Normand, J., Perrin, A., Planchu, G., and Froment, R. (1965). Les ruptures pariétales et septales aus cours des infarctus myocardiques (a propos de 30 observations anatomo-cliniques). Archives des Maladies du Coeur, et des Vaisseaux, 58, 1311.

Osher, H. L., and Wolff, L. (1952). The diagnosis of infarction of the interventricular septum. American Heart fournal, 45, 429.

Wood, P. (1948). Electrocardiographic appearances in acute and chronic pulmonary heart disease. British Heart fournal, 10, 87.

Requests for reprints to Dr. Finlay Kerr, Raigmore Hospital, Inverness. 